\title{
Guía de manejo de terapia antitrombótica durante procedimientos endoscópicos
}

\author{
Mario Peláez-Luna ${ }^{1,2 *}$, Claudia Isabel Blanco-Vela ${ }^{3,4}$, Clara Luz Martínez-García ${ }^{3}$, \\ Angélica I. Hernández-Guerrero ${ }^{5}$, Sergio Solana-Sentíes ${ }^{6}$, Orlando Bada-Yllán ${ }^{7}$, Jony Cerna-Cardona ${ }^{8}$, \\ Héctor Espino-Cortés ${ }^{9}$, Yu Ling Lee-Tsai ${ }^{10}$, Hugo Roberto Leytón-Rivera ${ }^{10}$, Claudia Martínez-Camacho ${ }^{10}$, \\ Enrique Murcio-Pérez ${ }^{11}$, Francisco Alejandro Ovando-Zambrano ${ }^{12}$, Fernando Pérez-Aguilar ${ }^{13}$, \\ Roberto Ramos-González ${ }^{14}$, Ángel Andrés Reyes-Dorantes ${ }^{3}$, Carlos Alberto Reyes-Gómez ${ }^{3}$, \\ Xochiquetzal Sánchez-Chávez ${ }^{15}$, Javier Ignacio Vinageras-Barroso ${ }^{16}$ y Luis Eduardo Zamora-Nava ${ }^{2}$
}

${ }^{1}$ División de Investigación, Facultad de Medicina, UNAM; ${ }^{2}$ Instituto Nacional de Ciencias Médicas y Nutrición Salvador Zubirán; ${ }^{3}$ Hospital San Ángel Inn; ${ }^{4}$ Hospital Central Militar; ${ }^{5}$ nstituto Nacional de Cancerología; ${ }^{6} \mathrm{Hospital}$ Central Ignacio Morones Prieto; ${ }^{7}$ Hospital General Dr. Manuel Gea González; ${ }^{8} \mathrm{Hospital}$ Juárez de México; ${ }^{9} \mathrm{Hospital}$ General de México; ${ }^{10} \mathrm{Hospital}$ General Regional N. ${ }^{\circ}$ Dr. Carlos McGregor Sánchez Navarro, IMSS; ${ }^{11}$ Hospital de Especialidades CMN SXXI, IMSS; ${ }^{12}$ Hospital de Cardiología CMN SXXI, IMSS; ${ }^{13}$ Hospital General Fernando Quiróz, Ciudad de México; ${ }^{14} \mathrm{Hospital}$ Arboledas, IMSS, Jalisco; ${ }^{15} \mathrm{Hospital}$ Ángeles del Pedregal; ${ }^{16} \mathrm{Hospital} \mathrm{Español,} \mathrm{Ciudad} \mathrm{de} \mathrm{México,} \mathrm{México}$

\section{Resumen}

El uso de terapias antitrombóticas y de antiinflamatorios no esteroideos ha aumentando progresivamente, lo cual incrementa el riesgo de hemorragia. Entre las causas y sitios de hemorragia asociada a estas terapias están aquellos que suceden alrededor de un procedimiento invasivo como la endoscopia. En los pacientes que reciben terapia antitrombótica y que serán sometidos a algún procedimiento endoscópico se debe equilibrar el riesgo de hemorragia frente al riesgo trombótico, para minimizar el tiempo en que el paciente estará sin la debida protección antiplaquetaria o anticoagulante. El manejo de la terapia antitrombótica durante una endoscopia se ha hecho más complejo debido al desarrollo de anticoagulantes de acción directa. Aunque existen guías y revisiones internacionales sobre el manejo de estos fármacos en relación con procedimientos endoscópicos, el idioma de publicación, y la disponibilidad y accesibilidad de medicamentos limitan el acceso a ellas, así como su aplicabilidad ad integrum; esto justifica su revisión y adaptación a México. La Asociación Mexicana de Endoscopia Gastrointestinal convocó a un grupo de gastroenterólogos, cardiólogos, hematólogos y endoscopistas para revisar y evaluar de manera crítica la evidencia científica para proponer estrategias de manejo de la terapia antitrombótica antes, durante y después de algún procedimiento endoscópico. El objetivo es sugerir alternativas de acuerdo con la disponibilidad de recursos humanos y tecnológicos en nuestro país basadas en la evidencia científica disponible en la actualidad.

Palabras clave: Endoscopia. Anticoagulantes. Antiplaquetarios. Anticoagulantes de acción directa. Hemorragia digestiva. Trombosis. Embolia.

\footnotetext{
Correspondencia:

Mario Peláez-Luna

INCMNSZ

Vasco de Quiroga, 15

Col. Belisario Domínguez, Sección XVI, Del. TlalpanFecha de recepción: 27-12-2018

C.P. 14080, Ciudad de México, México Fecha de aceptación: 02-02-2019

E-mail: mariopl@prodigy.net.mx DOI: 10.24875/END.M19000007

Disponible en internet: 06-05-2019

Endoscopia. 2019;31:58-76

www.endoscopia-ameg.com

0188-9893/๑ 2019. Asociación Mexicana de Endoscopia Gastrointestinal, publicado por Permanyer México SA de CV, todos los derechos reservados.
} 


\title{
Guide for the management of antithrombotic therapy during endoscopic procedures
}

\begin{abstract}
The use of antithrombotic therapies and non-steroid anti-inflammatory drugs has increased worldwide and with it the risk of presenting a bleeding complication. The group of patients undergoing an invasive procedure such as a gastrointestinal endoscopy are at a higher risk of peri-procedural bleeding complications. However, in those patients receiving anti-thrombotic therapy scheduled for a gastrointestinal endoscopy the risk of bleeding must be weighted against the risk of a thrombo-embolic event while the patients are off the antithrombotic treatment. Antithrombotic drug management in the peri-endoscopic time has become more complex due to the appearance of the new direct action anticoagulants. Although several international guidelines and systematic reviews on the topic are available, its applicability and availability in Mexico are limited, considering language barriers and drug and technology availability, among others. This lead the Asociación Mexicana de Endoscopia Gastrointestinal to summon a group of gastroenterologists, endoscopists, cardiologists and hematologists to assess and review current scientific evidence with the aim to develop and propose a series of recommendations for the management of anti-thrombotic therapy before, during and after and endoscopic procedure.
\end{abstract}

Key words: Endoscopy. Anticoagulants. Antiplatelet therapy. Direct action anticoagulants. Gastrointestinal bleeding. Thrombosis. Embolism.

\section{Introducción}

El uso de terapias antitrombóticas y de antiinflamatorios no esteroideos (AINE) ha aumentado progresivamente, lo cual incrementa el riesgo de hemorragia'. Entre las causas y sitios de hemorragia asociada a estas terapias están aquellos que suceden en relación con un procedimiento invasivo (cirugía, endoscopias, etc.), hemorragias intracraneales y gastrointestinales ${ }^{2}$.

Algunos autores han sugerido que debido al corto tiempo con el que se suspenden estos medicamentos antes de un procedimiento, el riesgo de hemorragia y trombosis puede estar subestimado ${ }^{3}$.

La terapia antitrombótica incluye tanto los antiplaquetarios como a los anticoagulantes y constituye uno de los aspectos esenciales en el cuidado de los pacientes con enfermedades cardiovasculares.

En los pacientes que reciben terapia antitrombótica y que serán sometidos a algún procedimiento invasivo como la endoscopia gastrointestinal se debe equilibrar adecuadamente el riesgo de hemorragia frente al riesgo trombótico (arterial o venoso). Esto se debe valorar de manera individual para minimizar el tiempo en que el paciente estará sin la debida protección antiplaquetaria $\mathrm{o}$ anticoagulante.

Para brindar el mayor beneficio a los pacientes en la toma de decisiones, es necesario conocer los diferentes fármacos disponibles, sus indicaciones y vida media; además de realizar una evaluación multidisciplinaria y consensuada que incluya a los médicos responsables de la terapia antitrombótica (p. ej., cardiólogos, neurólogos) y preferentemente un hematólogo, lo cual puede garantizar un tratamiento individualizado y seguro.
El manejo de la terapia antitrombótica durante una endoscopia se ha hecho más complejo debido al desarrollo y prescripción de anticoagulantes de acción directa (AAD), cada uno de los cuales cuenta con potencia y vida media distintas.

Existen diversas guías y revisiones internacionales ${ }^{4-8}$ que sugieren alternativas y métodos de manejo de la terapia antitrombótica en procedimientos invasivos, incluyendo los endoscópicos; sin embargo, el idioma de publicación, y la disponibilidad y accesibilidad de medicamentos limita el acceso a ellas, así como su aplicabilidad ad integrum; esto justifica su revisión y adaptación a México. En junio 2018 la Asociación Mexicana de Endoscopia Gastrointestinal (AMEG) convocó a un grupo de gastroenterólogos, cardiólogos, hematólogos y endoscopistas para revisar los avances en diferentes aspectos del manejo de la terapia antitrombótica durante el periodo periendoscópico y evaluar de manera crítica la evidencia científica para proponer estrategias de manejo mediante un consenso.

El objetivo de las guías de manejo de la terapia antitrombótica durante procedimientos endoscópicos es sugerir alternativas de acuerdo con la disponibilidad de recursos humanos y tecnológicos en nuestro país basadas en la evidencia científica disponible en la actualidad.

\section{Métodos}

Para preparar y realizar la elaboración de guías consensuadas se utilizó el método Delphi ${ }^{\circ}$. Se crearon cuatro mesas de trabajo y a cada una se le asignó un 
tema específico que representa cada una de las secciones de la presente guía. Cuatro de los participantes realizaron una búsqueda en la base de datos PubMed de artículos publicados a manera de resumen 0 artículo completo en los idiomas inglés y español. Se dio preferencia a revisiones sistemáticas, metaanálisis, guías de práctica clínica, consensos, ensayos clínicos controlados y cohortes, aunque no se limitó a este tipo de manuscritos.

Una vez concluida la búsqueda se elaboraron enunciados relacionados con el tema de cada mesa y fueron enviados a cada coordinador de mesa junto con la bibliografía seleccionada. Cada coordinador asignó aleatoriamente uno o más enunciados a cada participante, quien calificó la evidencia que los apoya.

Para calificar la evidencia se utilizó el sistema GRADE (Grading of Recommendations, Assessment, Development and Evaluation) modificado para calificar la calidad de la evidencia publicada y seleccionar los artículos más relevantes sin importar si los resultados eran positivos o negativos ${ }^{10}$.

Con la finalidad de homogeneizar la forma de evaluación y que cada participante conociera el método, se les pidió y envió un enlace electrónico para concluir el curso en línea gratuito Up to Date del sistema GRADE.

Este sistema tiene el objetivo de mejorar la evaluación de la calidad de la evidencia y la fuerza con la que esta se recomienda. En él la graduación de la calidad no se basa en el tipo de estudio (diseño y metodología), sino que se consideran también los desenlaces (pertinencia, relevancia, etc.), así como las preguntas elaboradas para estudiar dicho desenlace. De tal forma que aunque la evidencia de mayor calidad se origina en revisiones sistemáticas, ensayos clínicos, etc., el sistema GRADE clasifica la calidad tanto con base en el diseño y métodos utilizados para evaluar los desenlaces preseleccionados o responder una pregunta tipo PICO (Población o Pacientes, Intervención o Indicador, Control o Comparación y O de desenlace por su traducción del inglés Outcome) elaborada con anterioridad y con fines específicos. Esto permite que pueda considerarse evidencia de menor calidad (p. ej., casos y controles, estudios transversales, series de casos) ${ }^{11}$.

La calidad de la evidencia puede ser «alta» cuando la seguridad o confianza en los desenlaces o efectos estimados no puede o no podría ser modificada por investigaciones subsecuentes. Se considera «moderada" cuando investigaciones posteriores podrían modificar los efectos o desenlaces y, por lo tanto, nuestra confianza en la información actual disminuye. La
Tabla 1. Evaluación GRADE

\begin{tabular}{|l|l|}
\hline Niveles de calidad & Definición \\
\hline Alto & $\begin{array}{l}\text { Alta confianza en la coincidencia entre } \\
\text { el efecto real y el estimado }\end{array}$ \\
\hline Moderado & $\begin{array}{l}\text { Moderada confianza en la estimación del } \\
\text { efecto. Hay posibilidad de que el efecto } \\
\text { real esté alejado del efecto estimado }\end{array}$ \\
\hline Bajo & $\begin{array}{l}\text { Confianza limitada en la estimación del } \\
\text { efecto. El efecto real puede estar lejos } \\
\text { del estimado }\end{array}$ \\
\hline Muy bajo & $\begin{array}{l}\text { Poca confianza en el efecto estimado. } \\
\text { El efecto verdadero muy probablemente } \\
\text { sea diferente del estimado }\end{array}$ \\
\hline
\end{tabular}

GRADE: Grading of Recommendations, Assessment, Development and Evaluation.

calidad es «baja» cuando es muy probable que la información actual se modifique con estudios ulteriores y «muy baja» cuando los desenlaces o efectos en estudio conocidos en la actualidad son extremadamente inciertos (Tabla 1).

La calidad y fuerza de recomendación (débil o fuerte) se expresan como letras mayúsculas de la «A» a la «D» (que indican la calidad de evidencia, A para muy alta calidad y $D$ para muy baja calidad) y números (que indican la fuerza de recomendación a favor o en contra, 1 para fuerte y 2 para débil) (Tabla 2).

Estos enunciados y su calificación fueron presentados por los coordinadores a los miembros de sus mesas donde se revisó el contenido y redacción de estos efectuando modificaciones en conjunto además de discutir la pertinencia o necesidad de eliminar 0 agregar otros enunciados. Se votó «en acuerdo» o «en desacuerdo" para cada enunciado. Cuando el acuerdo era mayor al $75 \%$ se concluyó que el enunciado permanecería sin modificaciones, y cuando el acuerdo era menor al $75 \%$ se realizaron modificaciones en contenido y redacción, sometiéndose nuevamente a votación, y así sucesivamente hasta llegar a un acuerdo mayor al $75 \%$.

Aquellos enunciados con desacuerdo mayor al $75 \%$, repetidos o redundantes fueron eliminados del proceso. Posteriormente a la reunión cada coordinador y los miembros de cada mesa desarrollaron comentarios y consideraciones finales a cada enunciado, además de revisar y determinar el nivel y calidad de evidencia que lo apoya, así como la fortaleza de la recomendación, basándose en el sistema modificado de GRADE antes mencionado. 
Tabla 2. Recomendaciones GRADE

\begin{tabular}{|c|c|c|c|}
\hline Grado de recomendación & Claridad del riesgo/beneficio & Calidad de la evidencia de apoyo & Implicaciones \\
\hline $\begin{array}{l}\text { 1A } \\
\text { Recomendación fuerte/ } \\
\text { calidad de evidencia alta }\end{array}$ & $\begin{array}{l}\text { Los beneficios claramente } \\
\text { superan los riesgos o } \\
\text { viceversa }\end{array}$ & $\begin{array}{l}\text { Evidencia consistente proveniente de } \\
\text { ensayos controlados y aleatorizados o } \\
\text { bien evidencia convincente de alguna } \\
\text { otra forma. Estudios posteriores } \\
\text { difícilmente impactarán nuestra } \\
\text { confianza y cambiarán el estimado de } \\
\text { los riesgos y beneficios }\end{array}$ & $\begin{array}{l}\text { Las recomendaciones } \\
\text { fuertes pueden aplicarse } \\
\text { a todos los casos en casi } \\
\text { todas las circunstancias }\end{array}$ \\
\hline $\begin{array}{l}\text { Recomendación fuerte/ } \\
\text { calidad de evidencia } \\
\text { moderada }\end{array}$ & $\begin{array}{l}\text { Los beneficios claramente } \\
\text { superan los riesgos o } \\
\text { viceversa. Existe } \\
\text { incertidumbre en los } \\
\text { estimados de riesgo y } \\
\text { beneficio }\end{array}$ & $\begin{array}{l}\text { Evidencia de ensayos clínicos } \\
\text { controlados con limitaciones } \\
\text { importantes (resultados inconsistentes, } \\
\text { fallas metodológicas o imprecisiones), o } \\
\text { evidencia muy fuerte de estudios con } \\
\text { otro diseño. Investigaciones futuras (si } \\
\text { se realizan) pueden impactar la } \\
\text { confianza y modificar los beneficios y } \\
\text { riesgos estimados }\end{array}$ & $\begin{array}{l}\text { Recomendación fuertes } \\
\text { que podría aplicarse a } \\
\text { todos los casos en casi } \\
\text { todas las circunstancias a } \\
\text { menos que existan una } \\
\text { alternativa clara } \\
\text { congruente y racional }\end{array}$ \\
\hline $\begin{array}{l}\text { 1C } \\
\text { Recomendación fuerte/ } \\
\text { calidad de evidencia baja }\end{array}$ & $\begin{array}{l}\text { Los beneficios aparentemente } \\
\text { superan los riesgos o } \\
\text { viceversa }\end{array}$ & $\begin{array}{l}\text { Evidencia de estudios } \\
\text { observacionales, experiencia clínica } \\
\text { no sistematizada o de ensayos } \\
\text { clínicos controlados con errores } \\
\text { serios. Cualquier estimación de riesgo } \\
\text { o beneficio es incierto }\end{array}$ & $\begin{array}{l}\text { La recomendación fuerte } \\
\text { puede aplicarse a casi } \\
\text { todos los pacientes, pero } \\
\text { la evidencia que la apoya } \\
\text { es de baja calidad }\end{array}$ \\
\hline $\begin{array}{l}2 \mathrm{~A} \\
\text { Recomendación débil con } \\
\text { evidencia de calidad alta }\end{array}$ & $\begin{array}{l}\text { Los beneficios están } \\
\text { equilibrados respecto o son } \\
\text { similares a los riesgos }\end{array}$ & $\begin{array}{l}\text { Evidencia consistente proveniente de } \\
\text { ensayos controlados y aleatorizados o } \\
\text { bien evidencia convincente de alguna } \\
\text { otra forma. Estudios posteriores } \\
\text { difícilmente impactarán nuestra } \\
\text { confianza y cambiarán el estimado } \\
\text { de los riesgos y beneficios }\end{array}$ & $\begin{array}{l}\text { La recomendación débil } \\
\text { implica que la mejor } \\
\text { acción o estrategia puede } \\
\text { cambiar dependiendo de } \\
\text { las circunstancias clínicas } \\
\text { y sociales de cada caso }\end{array}$ \\
\hline $\begin{array}{l}\text { 2B } \\
\text { Recomendación débil/ } \\
\text { calidad de evidencia } \\
\text { moderada }\end{array}$ & $\begin{array}{l}\text { Los beneficios están } \\
\text { equilibrados respecto o son } \\
\text { similares a los riesgos. Existe } \\
\text { incertidumbre en los } \\
\text { estimados de riesgo y } \\
\text { beneficio }\end{array}$ & $\begin{array}{l}\text { Evidencia de ensayos clínicos } \\
\text { controlados con limitaciones } \\
\text { importantes (resultados inconsistentes, } \\
\text { fallas metodológicas o imprecisiones), o } \\
\text { evidencia muy fuerte de estudios con } \\
\text { otro diseño. Investigaciones futuras (si } \\
\text { se realizan) pueden impactar la } \\
\text { confianza y modificar los beneficios y } \\
\text { riesgos estimados }\end{array}$ & $\begin{array}{l}\text { Recomendación débil. } \\
\text { Manejos alternativos } \\
\text { pueden considerarse } \\
\text { mejores en algunos } \\
\text { pacientes y bajo ciertas } \\
\text { circunstancias }\end{array}$ \\
\hline $\begin{array}{l}2 \mathrm{C} \\
\text { Recomendación débil/ } \\
\text { calidad de evidencia baja }\end{array}$ & $\begin{array}{l}\text { Incertidumbre en los } \\
\text { estimados de riesgo y } \\
\text { beneficio. Los beneficios } \\
\text { posiblemente están } \\
\text { equilibrados respecto o son } \\
\text { similares a los riesgos }\end{array}$ & $\begin{array}{l}\text { Evidencia de estudios observacionales, } \\
\text { experiencia clínica no sistematizada o } \\
\text { de ensayos clínicos controlados con } \\
\text { errores serios. Cualquier estimación de } \\
\text { riesgo o beneficio es incierto }\end{array}$ & $\begin{array}{l}\text { Recomendación muy } \\
\text { débil. Otras alternativas } \\
\text { pudieran ser igualmente } \\
\text { razonables }\end{array}$ \\
\hline
\end{tabular}

GRADE: Grading of Recommendations, Assessment, Development and Evaluation.

Esta guía puede y deberá ser revisada y editada periódicamente de acuerdo con la necesidad de incorporar cambios y avances tecnológicos, así como información nueva y relevante. Las recomendaciones presentadas y su fuerza se basan en la revisión de la evidencia científica disponible en el momento de su elaboración, así como en la discusión y evaluación de los riesgos y beneficios hecha por los participantes de la guía. Es importante recordar que esta, como todas las guías, presenta información que pretende ayudar a los involucrados en el cuidado de pacientes y no debe considerarse como reglas ni estándares de cuidado inmodificables, puesto que las decisiones clínicas deben individualizarse y suelen ser resultado de un análisis detallado de la situación clínica del paciente y los recursos disponibles que pudieran o no estar en acuerdo con este documento. 
Tabla 3. Anticoagulantes orales

\begin{tabular}{|c|c|c|c|c|}
\hline Fármaco & Mecanismo de acción & Vida media & Eliminación & Dosis inicial \\
\hline Rivaroxabán & Inhibidor directo del factor $\mathrm{Xa}$ & $5-9 \mathrm{~h}$ & Renal $66 \%$ & $\begin{array}{l}20 \mathrm{mg} \\
\text { Cada } 24 \mathrm{~h}\end{array}$ \\
\hline Apixabán & Inhibidor directo del factor $\mathrm{Xa}$ & 8-14 h & Renal $25 \%$ & $\begin{array}{l}5 \mathrm{mg} \text { cada } \\
12 \mathrm{~h}\end{array}$ \\
\hline Edoxabán & Inhibidor directo del factor $\mathrm{Xa}$ & $10-14 \mathrm{~h}$ & $\begin{array}{l}\text { Hepática 50\% } \\
\text { Renal } 50 \%\end{array}$ & $\begin{array}{l}60 \mathrm{mg} \\
\text { cada } 24 \mathrm{~h}\end{array}$ \\
\hline Dabigatrán & Inhibidor directo del factor Ila & $12-17 \mathrm{~h}$ & Renal $80 \%$ & $\begin{array}{l}150 \mathrm{mg} \\
\text { cada } 12 \mathrm{~h}\end{array}$ \\
\hline $\begin{array}{l}\text { Acenocumarina } \\
\text { Warfarina }\end{array}$ & $\begin{array}{l}\text { Antagonista de los factores } \\
\text { dependientes de la vitamina K }\end{array}$ & $\begin{array}{l}9-12 \mathrm{~h} \\
35-50 \mathrm{~h}\end{array}$ & Hepática & $\begin{array}{l}\text { Variable } \\
1 \text { tableta día } \\
\text { INR } 2-3\end{array}$ \\
\hline
\end{tabular}

INR: razón internacional normalizada.

\section{Definición de agentes antitrombóticos}

\section{Los anticoagulantes son sustancias químicas que, de manera directa o indirecta, inhiben la formación del coágulo y están indicados en la prevención y tratamiento de la enfermedad tromboembólica}

\section{Recomendación fuerte, calidad de la evidencia alta (GRADE 1A)}

Los anticoagulantes son fármacos que inhiben la formación de coágulos o causan su destrucción y están indicados en la prevención y tratamiento de la trombosis venosa profunda, embolia pulmonar, trombofilia, síndrome coronario agudo, prevención de la embolización sistémica en pacientes con fibrilación auricular o con válvulas cardíacas metálicas y después de la colocación de endoprótesis coronarias (Tabla 3).

Los antagonistas de vitamina K (AVK) como la warfarina y el acenocumarol se encuentran entre los anticoagulantes orales (ACO) utilizados con mayor frecuencia. Estos inhiben el ciclo de interconversión de la VK, que es el cofactor esencial para la síntesis hepática de las proteínas dependientes de la VK, que incluyen a los factores de coagulación II, VII, IX y X, así como a las proteínas anticoagulantes $\mathrm{C}$ y $\mathrm{S}$.

Estos ACO inducen la síntesis defectuosa de todas las proteínas dependientes de la VK. Los ACO dicumarínicos tienen un estrecho margen terapéutico y requieren monitorización de la razón internacional normalizada (INR por sus siglas en inglés) para dar la dosis apropiada ${ }^{12,13}$
La respuesta de cada paciente a estos fármacos es variable y multifactorial. Tienen interacciones con varios fármacos y alimentos que aumentan o disminuyen su efecto, como el consumo de alimentos que contienen VK que atenúan su efecto (p. ej., hojas verdes, aguacate, moronga e hígado) ${ }^{12}$ (Tabla 4).

Los anticoagulantes orales directos (ACOD) incluyen el rivaroxabán, el apixabán y el edoxabán, que tienen como blanco terapéutico único al factor Xa de la coagulación. Otros, como el etexilato dabigatrán, bloquean al factor lla.

La acción de los ACOD es más estable y predecible comparado con los AVK. Los ACOD no requieren modificación de la dosis ni de monitorización; su efecto inicia y termina más rápidamente que el de los dicumarínicos ${ }^{12,13}$. Es importante recordar que no es posible monitorizar el efecto de los ACOD con pruebas de coagulometría convencionales.

El etexilato de dabigatrán es un profármaco con vida media de 12 a 17 horas, solo un $30 \%$ se une a proteínas, por lo que la hemodiálisis puede acelerar su depuración. Se elimina sin cambios por vía renal casi en un $80 \%$, por lo que los pacientes con depuración de creatinina $<30 \mathrm{ml} / \mathrm{min}$ no deben usarlo. Su antídoto específico (idarucizumab) es muy costoso.

El rivaroxabán tiene una vida media de 5 a 9 horas, no es hemodializable, se elimina por vía renal, se metaboliza en el hígado y su antídoto específico es el andexanet.

El apixabán tiene una vida media de 8 a 14 horas, no es dializable, el $30 \%$ se metaboliza en el hígado y se elimina vía renal12,13. 
Tabla 4. Fármacos que potencian o inhiben la acción de los antagonistas de la vitamina $\mathrm{K}$

\begin{tabular}{|l|l|}
\hline \multicolumn{2}{|c|}{$\begin{array}{c}\text { Interacciones significativas de anticoagulantes orales } \\
\text { antagonistas de vitamina K }\end{array}$} \\
\hline Medicamento & Efecto \\
\hline Amoxicilina & Aumenta \\
\hline Acido nalidíxico & Aumenta \\
\hline Atorvastatina & Aumenta \\
\hline Azatriopina & Disminuye \\
\hline Bezafibrato & Aumenta \\
\hline Cetirizina & Aumenta \\
\hline Ciclosporina & Aumenta \\
\hline Cimetidina & Aumenta \\
\hline Ciprofloxacino & Aumenta \\
\hline Cisaprida & Aumenta \\
\hline Claritromicina & Aumenta \\
\hline Diclofenaco & Aumenta \\
\hline Doxiciclina & Aumenta \\
\hline Fenofibrato & Aumenta \\
\hline Fluconazol & Aumenta \\
\hline Ibuprofeno & Aumenta \\
\hline Metronidazol & Aumenta \\
\hline Misoprostol & Aumenta \\
\hline Naproxeno & Aumenta \\
\hline Oifamicam & Aumenta \\
\hline
\end{tabular}

Los antiplaquetarios son sustancias que disminuyen la función plaquetaria mediante inhibición irreversible de la ciclooxigenasa o del receptor P2Y12 y están indicados en la prevención y tratamiento de la enfermedad tromboembólica arterial

\section{Recomendación fuerte, calidad de la evidencia alta (GRADE 1A)}

Los antiplaquetarios son fármacos que actúan sobre la capacidad de activación y agregación de las plaquetas, evitando la formación del coágulo ${ }^{14}$ (Tabla 5).
El tratamiento antiplaquetario está indicado en cardiopatías como el infarto agudo de miocardio (IAM), angina inestable o estable, tras una angioplastia, colocación de una endoprótesis coronaria o realización de un puente aortocoronario. También están indicados en enfermedades cerebrovasculares como el accidente isquémico transitorio, accidente vascular cerebral 0 endarterectomía carotídea, así como en trastornos vasculares periféricos de origen arterial ${ }^{14}$.

En algunas situaciones clínicas como fibrilación auricular, síndromes coronarios agudos y después de intervenciones coronarias percutáneas como la colocación de endoprótesis está indicado el tratamiento combinado con anticoagulantes y antiplaquetarios en doble o triple terapia ${ }^{4}$.

Los fármacos antiplaquetarios se clasifican en inhibidores de la ciclooxigenasa (COX), antagonistas del receptor del adenosindifosfato (ADP) e inhibidores de los receptores de glucoproteínas IIb/IIla ${ }^{12-14}$.

El ácido acetilsalicílico (AAS), por su parte, es un inhibidor de la COX-1; el AAS inhibe la síntesis del tromboxano A2 y causa la inactivación irreversible de la plaqueta durante toda su vida. La dosis de mantenimiento es de 75-150 mg/día.

El clopidogrel es un derivado de las tienopiridinas, antagoniza la agregación plaquetaria inducida por el ADP (agonista que recluta plaquetas y propaga el trombo arterial). Se metaboliza en hígado y su metabolito activo se une de manera covalente al residuo cisteína de uno de los receptores del ADP, el P2Y12, que causa agregación plaquetaria persistente.

La unión del clopidogrel y el P2Y12 provoca una modificación irreversible del receptor durante toda la vida de la plaqueta. Debido a esta inhibición irreversible se recomienda suspender el tratamiento al menos cinco días antes de una cirugía, que es el tiempo necesario para el recambio plaquetario. Otros ejemplos de antagonistas del receptor de ADP son el prasugrel y el ticagrelor.

\section{La frecuencia de hemorragia en procedimientos endoscópicos en pacientes con terapia antitrombótica depende del tipo de procedimiento realizado}

\section{Recomendación fuerte, calidad de la evidencia moderada (GRADE $1 \mathrm{~B}$ )}

Más de seis millones de personas en los EE.UU. reciben fármacos anticoagulantes para prevención de tromboembolia. Se estima que, anualmente, el $10 \%$ de 
Tabla 5. Fármacos antiplaquetarios orales

\begin{tabular}{|c|c|c|c|c|}
\hline Fármaco & Mecanismo de acción & Dosis recomendada & Vida media & $\begin{array}{l}\text { Metabolismo } \\
\text { Vía de eliminación }\end{array}$ \\
\hline Ácido acetilsalicílico & $\begin{array}{l}\text { Inhibidor de COX-1, inhiben la } \\
\text { síntesis de tromboxano A2 }\end{array}$ & 75-150 mg día & $2-19 h$ & $\begin{array}{l}\text { Met. hepático } \\
\text { Elim. renal }\end{array}$ \\
\hline Triflusal & $\begin{array}{l}\text { Inhibe la fosfodiesterasa del AMPc } \\
\text { y del GMPc plaquetario }\end{array}$ & 300 mg día & $34 \mathrm{~h} \pm 5 \mathrm{~h}$ & $\begin{array}{l}\text { Met. hepático } \\
\text { Elim. renal }\end{array}$ \\
\hline Clopidogrel & $\begin{array}{l}\text { Antagonista del receptor ADP } \\
\text { P2Y12 }\end{array}$ & 75 mg día & $6 \mathrm{~h}$ & $\begin{array}{l}\text { Met. hepático } \\
\text { Elim. renal } 60 \% \\
\text { Heces } 50 \%\end{array}$ \\
\hline Prasugrel & $\begin{array}{l}\text { Antagonista del receptor ADP } \\
\text { P2Y12 }\end{array}$ & $\begin{array}{l}60 \mathrm{mg} \text { dosis inicial } \\
\text { Posteriormente } \\
10 \mathrm{mg} \text { día }\end{array}$ & $2-15 \mathrm{~h}$ & $\begin{array}{l}\text { Met. hepático } \\
\text { Elim. renal } 68 \%\end{array}$ \\
\hline Ticagrelor & $\begin{array}{l}\text { Antagonista del receptor ADP } \\
\text { P2Y12 }\end{array}$ & $\begin{array}{l}180 \mathrm{mg} \text { dosis inicial } \\
\text { Posteriormente } \\
90 \mathrm{mg} \text { cada } 12 \mathrm{~h}\end{array}$ & $6-13 \mathrm{~h}$ & $\begin{array}{l}\text { Met. hepático } \\
\text { Elim. renal }\end{array}$ \\
\hline Dipiridamol & $\begin{array}{l}\text { Inhibe la agregación plaquetaria } \\
\text { aumentando AMPc plaquetario }\end{array}$ & 300 mg día & $10 \mathrm{~h}$ & Biliar \\
\hline Cilostazol & $\begin{array}{l}\text { Inhibidor selectivo de la } \\
\text { fosfodiesterasa III }\end{array}$ & $\begin{array}{c}50 \text { mg cada } 12 \text { h } \\
0 \\
100 \text { mg día }\end{array}$ & $11 \mathrm{~h}$ & $\begin{array}{l}\text { Met. hepático } \\
\text { Elim. Renal }\end{array}$ \\
\hline
\end{tabular}

ADP: difosfato de adenosina; AMPc: monofosfato de adenosina cíclico; COX-1: ciclooxigenasa 1; GMPc: monofosfato de guanosina cíclico.

Tabla 6. Riesgo de hemorragia posterior a procedimientos endoscópicos

Riesgo de hemorragia posterior a procedimientos endoscópicos

\begin{tabular}{l|l}
\hline Alto & Bajo
\end{tabular}

Polipectomía $(<1 \mathrm{~cm})$

Resección endoscópica de la mucosa

Disección endoscópica de la mucosa

Papilotomía

Esfinterotomía

Ultrasonido endoscópico con aspiración con aguja fina

Gastrostomía o yeyunostomía endoscópica

Tratamiento endoscópico de várices esofágicas

Procedimientos de dilatación endoscópica

Procedimientos endoscópicos sin biopsia: endoscopia superior, endoscopia transnasal, colonoscopia, ultrasonido endoscópico, cápsula endoscópica

Cistogastrostomía, ablación tumoral

Procedimientos endoscópicos con biopsia mediante pinzas de biopsia estándar (todos los anteriores excluyendo ultrasonido endoscópico con aspiración con aguja fina)

Prótesis esofágica o enteral

CPRE con prótesis biliar o pancreática sin esfinterotomía

Videocápsula endoscópica

POEM

Enteroscopia asistida con balón

Marcaje, coagulación térmica

CPRE: colangiopancreatografía retrógrada endoscópica; POEM: miotomía peroral endoscópica.

estos pacientes requiere algún procedimiento invasivo que obliga a suspender la terapia antitrombótica ${ }^{15,16}$.

Aunque el objetivo es minimizar los eventos tromboembólicos y la hemorragia en el periodo periprocedimiento, los datos de ensayos clínicos que pueden orientar en este escenario son limitados, y muchas recomendaciones derivan de cohortes de un solo centro. Además, los datos sobre las tasas de hemorragia específicas a cada procedimiento son escasas en esta población. En la tabla 6 se muestra el riesgo de hemorragia posterior a procedimientos endoscópicos.

El riesgo de hemorragia después de la biopsia endoscópica con o sin el cese de los antitrombóticos es bajo. Un estudio prospectivo que incluyó 3,758 pacientes que se sometieron a biopsias endoscópicas convencionales encontró que el $10.5 \%$ de los pacientes 
estaban recibiendo antitrombóticos, y en 286 de ellos no se suspendió este tratamiento. Después de una biopsia endoscópica se presentó hemorragia en seis casos (RM: 0.15\%; intervalo de confianza [IC] 95\%: $0.09-0.22 \%$ ), y solo uno de ellos continuaba tomando antitrombóticos. La incidencia de hemorragia después de la biopsia no fue mayor en los pacientes que continuaron con antitrombóticos en comparación con los otros $(0,35 \text { vs. } 0,14 \% ; p=0.38)^{16}$.

En el 2012 y con la finalidad de disminuir la incidencia de eventos tromboembólicos, la revisión de las guías japonesas sugirió no suspender los agentes antitrombóticos durante el tratamiento endoscópico. El impacto de esta modificación sobre la frecuencia de complicaciones hemorrágicas después de los procedimientos colonoscópicos fue investigado mediante un estudio que evaluó la frecuencia de hemorragia pospolipectomía (HPP) en dos periodos en que se realizaron colonoscopias de vigilancia. El primer periodo, que sirvió como control, comprendió el año anterior al inicio de las nuevas guías y el segundo periodo comprendió dos años después de que se implementaron las nuevas directrices. Aunque la tasa de HPP no fue diferente antes y después de la revisión de las guías ( 0.87 vs. $1.01 \%)$, sí se encontró que, comparando usuarios de antitrombóticos vs. los no usuarios, la tasa de HPP fue de 0.60 y $3.13 \%$, respectivamente (RM: $5.11 ; p=0.0001$ ). En el análisis multivariante se encontró que la terapia puente con heparina (RM: $6.34 ; p=0.0002$ ), continuación de dosis baja de AAS (RM: $5.30 ; p=0.0079$ ) y el tamaño de la lesión (RM: 1.06; $p<0.0001)$ son factores de riesgo asociados a HPP17.

Un estudio multicéntrico de 270 pacientes bajo tratamiento antitrombótico a los que se les realizó biopsia endoscópica de la mucosa $(n=221)$ y resección endoscópica de la mucosa (REM) o disección submucosa endoscópica (DEM) $(n=49)$ encontró una tasa de hemorragia del $0.9 \%$ para la biopsia endoscópica de la mucosa y del $22 \%$ para la REM/DEM.

La tasa de hemorragia después de la biopsia endoscópica de la mucosa fue baja, incluso si se continuaban los fármacos antitrombóticos ( 0 vs. $1 \% ; p>0.99$, respectivamente), mientras que esta fue mayor cuando se usaba más de un fármaco antitrombótico en comparación con la monoterapia. (5.9 vs. $0 \% ; p<0.05)$. Con relación a la tasa de hemorragia después de REM/DEM, esta fue más alta en los usuarios de múltiples antitrombóticos, aunque no significativamente diferente al de los usuarios de un solo fármaco (33 vs. $14 \% ; p=0.17$ ). Tampoco se encontraron diferencias en las tasas de hemorragia de acuerdo con el cese o la continuación de los fármacos antitrombóticos (20 vs. $25 \% ; p=0.74$ ) y no se reportaron eventos de tromboembolia ${ }^{18}$.

\section{La frecuencia de tromboembolia posterior a la suspensión de la terapia antitrombótica depende del riesgo tromboembólico del paciente}

\section{Recomendación fuerte, calidad de la evidencia moderada (GRADE 1B)}

\section{Antiplaquetarios}

En los síndromes coronarios agudos existen periodos de mayor riesgo trombótico durante los cuales suspender la terapia dual con AAS y tienopiridina incrementa el riesgo de oclusión de endoprótesis vascular, IAM y la mortalidad hasta en un $50 \%$. Estos periodos de alto riesgo son: los 90 días posteriores al síndrome coronario agudo (independientemente del tratamiento con fármacos o con intervención coronaria percutánea), 30-45 días después de la colocación de endoprótesis vascular no medicada y 3-6 meses después de la colocación de endoprótesis vascular medicada ${ }^{19}$.

Cada año, al menos $10 \%$ de los pacientes que reciben anticoagulantes requieren interrupción del tratamiento para realización de cirugía o un procedimiento invasivo asociado a riesgo de hemorragia ${ }^{4,20}$. Existe una creciente preocupación por los riesgos asociados con la interrupción del AAS y otros antiagregantes en pacientes que se someten a procedimientos endoscópicos $^{20,21}$. Antes de suspenderlo debe considerarse no solo el riesgo de hemorragia, sino también el riesgo tromboembólico de acuerdo con sus antecedentes, temporalidad de los eventos previos e intensidad de la terapia antitrombótica (mono o multiterapia).

\section{Monoterapia}

Sundström, et al. ${ }^{22}$ en una cohorte poblacional de 601,527 usuarios de dosis bajas de AAS $(75-160 \mathrm{mg})$ examinaron el riesgo de eventos cardiovasculares (IAM, apoplejía, muerte cardiovascular) asociados a su interrupción. Encontraron que la interrupción de dosis bajas de AAS antes del procedimiento endoscópico incrementó la frecuencia de eventos cardiovasculares en más del $30 \%$, con una razón de riesgo estimado de 1.37 (IC 95\%: 1.34-1.41), el cual aumenta poco después de la interrupción y no disminuye con el tiempo. 


\section{Terapia dual}

El riesgo trombótico sin recibir terapia antiplaquetaria en la prevención secundaria es 10 veces más frecuente que en prevención primaria ( 3.11 vs. $0.34 \%$ por año) ${ }^{23}$. Una revisión sistemática observó una frecuencia del $75 \%$ de eventos trombóticos en pacientes en los cuales se descontinuó el AAS y la tienopiridina, así como una tasa de oclusión del endoprótesis vascular del $6 \%$ cuando se continuó el AAS pero se suspendió el clopidogrel. El tiempo promedio de aparición de los eventos fue de siete días cuando se suspendió el AAS y 120 días cuando se continuó esta ${ }^{24}$.

\section{Warfarina}

El riesgo de tromboembolia sin ACO es del $5 \%$ en pacientes con bajo riesgo tromboembólico, del 5-10\% en riesgo intermedio $y>10 \%$ en pacientes con alto riesgo tromboembólico ${ }^{1,9}$.

\section{Anticoagulantes orales directos}

La pérdida del efecto antitrombótico relacionado con la interrupción de los ACOD durante el periodo previo al procedimiento endoscópico es breve, debido a que tienen una vida media corta e inicio rápido de acción, por lo que el riesgo tromboembólico posterior a la suspensión con este tipo de fármacos es casi inexistente ${ }^{4,19,25}$.

En conclusión, el riesgo tromboembólico en pacientes en los cuales se suspende de manera temporal la terapia antitrombótica dependerá de la patología de base del paciente y el tipo de fármaco utilizado, por lo que cada caso debe individualizarse ${ }^{19,26}$.

\section{Agentes utilizados para revertir el efecto anticoagulante}

\section{LA DECISIÓN DE REVERTIR LA ANTICOAGULACIÓN DEBE SER EVALUADA POR UN EQUIPO MULTIDISCIPLINARIO, DEPENDERÁ DEL RIESGO TROMBOEMBÓLICO DEL PACIENTE Y EL RIESGO DE HEMORRAGIA ASOCIADA AL PROCEDIMIENTO}

\footnotetext{
Recomendación fuerte, calidad de la evidencia alta (GRADE 1A)

El riesgo de complicaciones en pacientes con terapia antitrombótica depende tanto del riesgo de hemorragia asociada al procedimiento como del riesgo de trombosis secundario a la interrupción del tratamiento.
}

A continuación, se describen las opciones para revertir el efecto antitrombótico y el momento en que deben utilizarse de acuerdo con el riesgo de hemorragia y trombosis.

\section{Antiplaquetarios}

Se ha encontrado que continuar la monoterapia con AAS es seguro durante y después de una polipectomía, incluso durante una esfinterotomía endoscópica ${ }^{27}$; no así para la disección endoscópica de la submucosa $(\mathrm{DES})^{28,29}$, la REM y la polipectomía de pólipos grandes $(>20 \mathrm{~mm})^{30,31}$, procedimientos en los que el riesgo de hemorragia se estima es mayor si se continúa el uso de AAS.

La REM en el tracto gastrointestinal superior confiere un alto riesgo de hemorragia, pero no hay estudios que estimen este riesgo asociado al uso de terapia continua con AAS.

Si bien algunas guías internacionales recomiendan la transfusión de plaquetas como una opción para los pacientes que toman antiplaquetarios y se presentan con hemorragia grave o que ponen en peligro la vida ${ }^{32}$, la presente guía no lo recomienda, pues consideramos no hay evidencia suficientemente sólida para respaldar dicha práctica. En una cohorte de 204 pacientes con hemorragia gastrointestinal y que recibían agentes antiplaquetarios, la transfusión de plaquetas no redujo la tasa de recurrencia de la hemorragia, pero se asoció a una mayor mortalidad ${ }^{33}$.

\section{Anticoagulantes orales}

Es evidente que el efecto de los AVK se revierte utilizando VK.

La VK es un agente de reversión común, utilizado en pacientes que reciben warfarina y requieren una disminución de la intensidad de la anticoagulación para disminuir el riesgo de complicaciones hemorrágicas.

La VK inicia su efecto dentro de las 4-6 horas posteriores a su administración y es completo después de 24-96 h. Su efecto es dependiente de la dosis y la vía de administración. Pacientes que recibieron dosis bajas de VK intravenosa IV (0.25-1.25 mg) tienen una reducción de la INR menor comparados con aquellos que recibieron dosis medias $(2-5 \mathrm{mg}) 0$ altas $(10 \mathrm{mg})$. La VK a dosis bajas logró una reversión parcial en la INR (1.5-2.0) a las $48 \mathrm{~h}$, mientras que la dosis media y alta consiguieron una reversión completa $(<1.5)$. En relación con la vía de administración, aquellos pacientes que recibieron VK vía oral (VO) experimentaron una 
reducción más gradual de la INR que los que la recibieron IV. En contraste con la VO, la administración IV logra reducciones más rápidas y globales en la INR ${ }^{34}$.

Debido al retraso en el efecto anticoagulante de la administración de la VK, en pacientes que se encuentren recibiendo antagonistas de vitamina VK y que requieran un procedimiento endoscópico urgente 0 bien se presente hemorragia durante un procedimiento endoscópico de alto riesgo, se recomienda el uso de complejo de concentrado de protombina (PCC).

EI PCC comprende compuestos derivados del plasma que contienen los factores de coagulación dependientes de la $\mathrm{VK}^{35}$. Por su capacidad para lograr una hemostasia rápida y efectiva, los PCC de cuatro factores (4FPCC) se consideran el estándar terapéutico para revertir de manera urgente a la warfarina ${ }^{36,37}$. La dosis para revertir el efecto anticoagulante según la INR se detalla en la tabla $7^{35}$.

En caso de no contar con PCC se puede usar plasma fresco congelado ( $\mathrm{PFC}$ ) administrado lo más próximo (minutos) al inicio del procedimiento, a dosis de 10-15 ml/kg/día en pacientes con coagulopatía o 15$30 \mathrm{ml} / \mathrm{kg} / \mathrm{día}$ en hemorragia aguda, con lo que se logra un nivel hemostático entre el 30 al 50\% de actividad de los factores de coagulación. Para lograr una elevación de la capacidad hemostática cercana al $100 \%$ se deben administrar $40 \mathrm{ml}$ de PFC/kg/día.

\section{Anticoagulantes orales directos Idarucizumab}

Es un fragmento de anticuerpo Fab monoclonal humanizado que se une al dabigatrán con una afinidad 350 veces mayor que la trombina y su uso clínico para revertir el efecto de este último está autorizado en la mayoría de los países. Después de su administración IV, el idarucizumab tiene una vida media de aproximadamente 45 minutos en pacientes con función renal normal y más prolongada en aquellos con insuficiencia renal ${ }^{38,39}$.

En un estudio en el que se administró $5 \mathrm{~g}$ de idarucizumab por vía IV en bolo de $50 \mathrm{ml}$ se observó una reducción rápida y completa de la actividad anticoagulante de dabigatrán en el 88 al $98 \%$ de los pacientes ${ }^{40}$.

\section{Andexanet ala}

Es un agente de reversión específico, diseñado para neutralizar los efectos anticoagulantes de los inhibidores directos e indirectos del factor $\mathrm{Xa}$. Es una proteína señuelo recombinante del factor Xa humano
Tabla 7. Dosis para revertir el efecto anticoagulante según la INR

\begin{tabular}{lcc}
\hline INR inicial & $\begin{array}{c}\text { Dosis mínima } \\
(\mathbf{U I} / \mathbf{k g})\end{array}$ & $\begin{array}{c}\text { Dosis máxima } \\
\text { (UI/kg) }\end{array}$ \\
$2.0-2.5$ & 22.5 & 32.5 \\
$2.5-3.0$ & 32.5 & 40 \\
$3.0-3.5$ & 40 & 47.5 \\
$>3.5$ & 47.5 & \\
No sobrepasar 3,000 UI. &
\end{tabular}

INR: razón internacional normalizada.

modificado que es catalíticamente inactiva, pero que conserva la capacidad de unirse a inhibidores del factor Xa en el sitio activo con alta afinidad y una relación estequiométrica de 1:1.

El andexanet se une y secuestra los inhibidores del factor Xa dentro del espacio vascular, restaurando así la actividad del factor Xa endógeno y reduciendo los niveles de actividad anticoagulante.

Se ha observado que la actividad anti-factor Xa se redujo hasta en un $94 \%$ de los pacientes tratados con apixabán y en el $92 \%$ de los tratados con rivaroxabán ${ }^{41}$. Esto indica que se necesitan dosis más altas para revertir de rivaroxabán o edoxabán que de apixabán, pues las concentraciones plasmáticas son más altas con la dosificación una vez al día que con dosificación de cada $12 \mathrm{~h}$, y porque el rivaroxabán y el edoxabán tienen mayores volúmenes de distribución que el apixabán.

En caso de no contar con estos fármacos, se puede usar PCC y como última opción la transfusión de PFC.

La decisión de utilizarlos deberá ser consensuada por un equipo multidisciplinario que valore el riesgo de hemorragia del procedimiento y el riesgo tromboembólico del paciente.

\section{Estratificación de riesgo}

\section{Se recomienda estratificar los} procedimientos endoscópicos en alto y bajo riesgo de acuerdo con la frecuencia de hemorragia

\section{Recomendación fuerte, calidad de la evidencia moderada (GRADE 1B)}

Los procedimientos endoscópicos varían en su potencial para ocasionar hemorragia considerable o no 
controlable. El riesgo de hemorragia en un procedimiento endoscópico depende del tipo de procedimiento y otros factores como el uso de antitrombóticos u otros escenarios clínicos como la aplicación de quimioterapia. La hemorragia puede presentarse inmediatamente posterior al procedimiento o de manera tardía (hasta dos semanas después) y se considera un evento mayor cuando el paciente requiere de hemotransfusión u hospitalización. El riesgo aumenta en pacientes bajo terapia antitrombótica ${ }^{42}$.

\section{BAJO RIESGO DE HEMORRAGIA}

Los procedimientos diagnósticos que incluyen toma de biopsia con pinzas estándar y aquellos que no conllevan un corte, inyección o dilatación se consideran de bajo riesgo de hemorragia, cuyo riesgo no supera el $1.5 \%{ }^{19}$ (Tabla 6$)$.

En un estudio de 13,233 pacientes sometidos a endoscopia superior a los que se les realizó biopsia de la mucosa no se reportó hemorragia o perforación. Estos datos confirman que el riesgo/beneficio de realizar una biopsia es favorable ${ }^{43}$. Sin embargo, hasta el momento no existen estudios que evalúen la seguridad de la toma de biopsias de la mucosa en pacientes tratados con los nuevos antiplaquetarios (prasugrel, ticagrelor, vorapaxar) o ACOD.

La colocación de endoprótesis enterales tiene un riesgo de hemorragia estimado entre el $0.5-1.2 \%$. Una revisión sistemática sobre la colocación exitosa de endoprótesis duodenales en pacientes con obstrucción gastroduodenal maligna sintomática reportó hemorragia en solo tres pacientes, lo que equivale a una tasa del $0.5 \%$, sin mortalidad alguna ${ }^{44}$. La presencia de hemorragia durante una enteroscopia de doble balón ha sido reportado en el $0.2 \%$ en pacientes sin ingesta de antitrombóticos ${ }^{45}$.

\section{Alto riesgo de hemorragia}

Son aquellos procedimientos con incidencia de hemorragia mayor al $1.5 \%$. Muchos de los procedimientos hemostáticos y/o terapéuticos se consideran en esta categoría ${ }^{4,24}$ (Tabla 6).

Dentro de los procedimientos que se realizan con mayor frecuencia está la polipectomía; esta se asocia a tasas de hemorragia posterior a la resección de entre el 0.3 y el $6.1 \%$, presentándose con mayor frecuencia cuando se utiliza corriente de corte pura. Los factores de riesgo de HPP incluyen: edad > 65 años, tamaño del pólipo $>1 \mathrm{~cm}$, enfermedad cardiovascular y uso de terapia antitrombótica ${ }^{46}$.

De acuerdo con un metaanálisis ${ }^{47}$, la hemorragia postesfinterotomía durante una colangiopancreatografía retrógrada endoscópica (CPRE) se presenta hasta en el $3.2 \%$ de los casos. Esta puede y suele ser tratada y controlada durante el procedimiento; no se ha registrado un incremento en su frecuencia con el uso de AAS o cuando se continúa el uso de clopidogrel o prasugrel, y suele ser menor cuando se usa corriente mixta comparado al uso de corriente de corte.

Otro metaanálisis observó que la mayoría de los eventos de hemorragia durante una CPRE se relacionan con la realización de esfinterotomía; la tasa de hemorragia en los procedimientos en los que no se realizó esfinterotomía es del $1.3 \%{ }^{48}$. Cuando la esfinterotomía se combina con esfinteroplastia, la incidencia de hemorragia es de hasta el $1.7 \%$, sin que exista diferencia significativa cuando se compara con la esfinterotomía sola.

Existen pocos estudios que evalúen el riesgo de hemorragia atribuible al uso de AAS u otros antitrombóticos y la escleroterapia o ligadura. De igual manera, la información sobre el riesgo de hemorragia durante o posterior a la colocación de una sonda de gastrostomía endoscópica percutánea es limitada. Se ha reportado que el riesgo de hemorragia no incrementa incluso en aquellos casos en que el AAS u otros antiagregantes no fueron suspendidos apropiadamente antes del procedimiento de acuerdo con las recomendaciones internacionales ${ }^{19,49}$.

Los procedimientos de resección y disección endoscópica son considerados de muy alto riesgo de hemorragia, con tasas que se sitúan entre el 1.8 y el $15.6 \%$; los porcentajes más elevados se observan en pacientes con uso de antitrombóticos y cuando el tamaño de la lesión resecada es $>4 \mathrm{~cm}^{50}$.

\section{Manejo de pacientes en procedimientos} de bajo riesgo de hemorragia

\section{En procedimientos endoscópicos con bajo riesgo de hemorragia no es necesario la estratificación del riesgo tromboembólico}

\section{Recomendación alta, calidad de la evidencia moderada (GRADE 1B)}

El que no sea necesario realizar una estratificación de riesgo tromboembólico en pacientes sometidos a procedimientos endoscópicos de bajo riesgo de 
hemorragia obedece a que la frecuencia de esta es muy baja, por lo que no es necesario suspender la terapia antitrombótica, de modo que la estratificación de riesgo de hemorragia no provocará modificaciones en el manejo de estos pacientes.

Un estudio prospectivo que evaluó la presencia de hemorragia asociada con la toma de biopsias endoscópicas en pacientes bajo tratamiento antitrombótico por alto riesgo de eventos tromboembólicos reportó que tras la toma de biopsias ocurre hemostasia espontánea en la totalidad de los casos, sin que se hayan observado complicaciones hemorrágicas durante las dos semanas de seguimiento (riesgo relativo [RR]: 0\%; IC 95\%: 0-3.6\%). No hubo diferencias significativas en el tiempo de hemorragia activa entre aquellos pacientes que tomaban uno 0 más fármacos antitrombóticos $(2.4 \pm$ 1.4 vs. $2.1 \pm 2.1$ minutos), y tampoco entre los que recibían o no warfarina $(2.3 \pm 1.8 \text { vs. } 2.2 \pm 1.8 \text { minutos })^{51}$.

De igual manera, un estudio multicéntrico realizado en Alemania reportó una baja tasa de hemorragia en procedimientos meramente diagnósticos, con una frecuencia de hemorragia del $0.002 \%$ en endoscopia superior y del $0.001 \%$ en colonoscopia ${ }^{52}$.

\section{En procedimientos endoscópicos con bajo riesgo de hemorragia no se requiere suspender antiplaquetarios}

\section{Recomendación fuerte, calidad de la evidencia baja (GRADE 1C)}

Ningún estudio ha demostrado un riesgo mayor de hemorragia en procedimientos endoscópicos de bajo riesgo y uso de antiagregantes. Un metaanálisis ${ }^{53}$ informó una incidencia del $0 \%$ de complicaciones hemorrágicas en procedimientos de dilatación endoscópica papilar con globo (bajo riesgo) y sugiere que el riesgo de complicaciones hemorrágicas en pacientes bajo terapia antiplaquetaria es muy bajo.

Un estudio multicéntrico que evaluó la seguridad de los procedimientos endoscópicos de tubo digestivo superior en usuarios de antiplaquetarios encontró una tasa de hemorragia del $0.9 \%$ después de la obtención de biopsias endoscópicas de la mucosa, lo que provocó la revisión y actualización de las Guías de la Sociedad de Gastroenterología y Endoscopia de Japón sobre la interrupción perioperatoria de la terapia antitrombótica ${ }^{54}$.

De tal forma que la terapia con medicamentos antitrombóticos únicos o dobles puede continuarse en todos los procedimientos diagnósticos, incluyendo aquellos en los que se realizarán biopsias endoscópicas de la mucosa y procedimientos considerados de bajo riesgo de hemorragia.

Esta conducta permite prevenir eventos de tromboembolia sin causar más hemorragia, incluso se recomienda continuar la administración de tienopiridinas en todos los procedimientos endoscópicos de bajo riesgo. Estudios previos informaron que la suspensión de AAS incrementó al triple el riesgo de infarto cerebral, el cual se llegó a presentar dentro de los primeros 10 días de la interrupción hasta en el $70 \%$ de los casos.

Se recomienda que los procedimientos endoscópicos electivos sean diferidos en pacientes con endoprótesis vasculares coronarias de colocación reciente hasta que el paciente haya recibido la terapia antitrombótica recomendada (mínimo seis semanas).

\section{En procedimientos endoscópicos de bajo riesgo de hemorragia se sugiere continuar los antagonistas de vitamina $\mathrm{K}$}

Recomendación fuerte, calidad de la evidencia débil (GRADE 1C)

En aquellos pacientes que vayan a ser sometidos a procedimientos endoscópicos de bajo riesgo de hemorragia se debe de continuar el uso del AVK ${ }^{32}$. Previamente al procedimiento debe asegurarse que la INR no exceda el rango terapéutico durante la semana previa al procedimiento. Si la INR se encuentra en el rango terapéutico se debe de continuar a la dosis indicada. Si la INR está por arriba del rango terapéutico, pero es menor a 5 , se debe de reducir la dosis diaria hasta que la INR se encuentre en rangos terapéuticos. Si la INR es mayor a 5, se debe de diferir la endoscopia y llamar al cardiólogo o hematólogo para ajustarlo.

Un estudio retrospectivo de 104 pacientes que fueron sometidos a 171 estudios endoscópicos de bajo riesgo mientras mantenían la dosis de warfarina reportó que aquellos a quienes se les suspendió la warfarina presentaron trombosis con una frecuencia del $0.7 \%$ (IC 95\%: 0.3-1.4) siendo esta la causa de muerte u otros efectos serios ${ }^{55,56}$.

En los procedimientos endoscópicos con bajo riesgo de hemorragia se sugiere continuar la terapia con anticoagulantes orales directos

Recomendación fuerte, calidad de la evidencia baja (GRADE 1C)

El uso y prescripción de ACOD como tratamiento a largo plazo en pacientes con riesgo cardiovascular ha 
aumentado considerablemente. Debido a su perfil farmacológico específico y vida media más corta y a un inicio de acción más rápido posterior a su reincorporación, el intervalo de suspensión preprocedimiento se reduce a 1-2 días en relación con el necesario con los AVK (5-7 días). La continuación o interrupción a corto plazo de la terapia con ACOD parece ser una estrategia segura en relación con el riesgo de hemorragia inherente al procedimiento endoscópico cuando este es de bajo riesgo ${ }^{8,19}$.

La evidencia para el manejo de ACOD en el entorno de un procedimiento endoscópico es escasa y las recomendaciones actuales se basan principalmente en opiniones de experto ${ }^{57,58}$.

El riesgo de hemorragia con el que contribuyen los ACOD durante un procedimiento endoscópico de bajo riesgo proviene de un estudio prospectivo y multicéntrico que evaluó 863 procedimientos de intervención menor (incluidos los endoscópicos) y mayores (quirúrgicos). Se reportó una mayor frecuencia de eventos cardiovasculares y hemorrágicos mayores en pacientes sometidos a procedimientos de intervención mayor (RR: $4.6 \%$; IC 95\%: $1.3-11.4 \%$ y RR: $8.0 \%$; IC $95 \%$ : 3.3-15.9\%, respectivamente) comparado con los procedimientos de intervención menor (RR: 0.8\%; IC 95\%: 0.3-1.8\%; $p=0.030$ y RR: $0.5 \%$; IC $95 \%$ : 0.0-1.4\%; $p<0.001$, respectivamente).

Al comparar las complicaciones cardiovasculares mayores en caso de no suspender los ACOD tanto en intervenciones menores y mayores, en 187 pacientes solo se observó 1 evento, mientras que en el grupo en el cual se suspendieron los ACOD y no se administró terapia de puente se reportaron 4 eventos en una muestra de 419, mientras que en el grupo en el que se suspendieron los ACOD y se administró terapia puente con heparina se reportaron 4 eventos en 257 pacientes. En relación a las complicaciones hemorrágicas mayores, se reportaron 0,3 y 7 eventos respectivamente en cada grupo mencionado ${ }^{57}$.

Algunos autores sugieren la suspensión del ACOD la mañana del día el estudio endoscópico, recomendando su reinicio temprano dentro de las 12 a 24 horas posterior a este, siempre tratando de equilibrar el riesgo de hemorragia con el riesgo de eventos tromboembólicos ${ }^{59}$.

En conclusión, la evidencia sugiere que los pacientes en terapia con ACOD pueden tratarse de forma segura en el entorno periprocedimiento de una endoscopia de bajo riesgo de hemorragia, con bajas tasas de eventos cardiovasculares y/o hemorragia.
Manejo de pacientes con alto riesgo de hemorragia

\section{En pacientes con bajo riesgo \\ tromboembólico que serán sometidos a procedimientos endoscópicos con alto riesgo de hemorragia la terapia con ácido acetilsalicílico debe continuarse}

\section{Recomendación fuerte, calidad de la evidencia moderada (GRADE 1B)}

Se recomienda continuar el tratamiento con AAS en todos los procedimientos endoscópicos con excepción de la DES, la REM en colon ( $>2 \mathrm{~cm}$ ), la REM en el tracto superior y la ampulectomía ${ }^{8}$.

Un estudio prospectivo en 1,657 pacientes a quienes se les realizó polipectomía observó que el uso concomitante de AAS no se asoció con mayor riesgo de $\mathrm{HPP}^{27}$. De igual manera, un estudio retrospectivo que evaluó el riesgo de hemorragia en esfinterotomía encontró que el uso de AAS durante la semana previa a la esfinterotomía no se asoció a mayor frecuencia de hemorragia; solo tres factores predijeron hemorragia: hemodiálisis, tiempo de protrombina prolongado al menos 2 segundos y hemorragia observada al momento de la esfinterotomía ${ }^{60}$.

Por el contrario, un estudio de 833 pacientes a quienes se les realizó DES por tumor gástrico observó que los casos que recibían terapia antitrombótica (46 AAS, 23 AAS + tienopiridinas y 21 AAS + warfarina) presentaron hemorragia posterior al procedimiento con mayor frecuencia en comparación con aquellos sin tratamiento antitrombótico (23.3 vs. $2 \%$, respectivamente) ${ }^{29}$. De manera similar, durante la realización de REM en 302 lesiones colónicas se presentó hemorragia tardía clínicamente significativa en el $7 \%$ de los casos, siendo los factores de riesgo: lesión en colon derecho (RM: $4.4 ; p=0.01$ ), uso de AAS (RM: $6.3 ; p=0.0005$ ) y la edad del paciente ${ }^{61}$.

\section{En pacientes que reciben terapia dual antiplaquetaria con alto riesgo tromboembólico y que se someterán a procedimientos endoscópicos con alto riesgo de hemorragia, se debe continuar el ácido acetilsalicílico pero suspender los antagonistas del receptor P2Y12}

\section{Recomendación fuerte, calidad de la evidencia moderada (GRADE 1B)}

Los pacientes con alto riesgo tromboembólico requieren el uso de terapia antiplaquetaria dual (AAS y 
antagonistas del receptor P2Y12) para evitar eventos cardiovasculares o eventos cerebrovasculares secundarios a trombosis arterial o venosa; sin embargo cuando estos requieran de procedimientos endoscópicos con alto riesgo de hemorragia, la terapia antiplaquetaria dual (p. ej., AAS + clopidogrel) incrementa el riesgo de hemorragia hasta 7.4 veces $^{55}$. El riesgo de hemorragia del procedimiento endoscópico no se incrementa con uso de AAS, sin embargo, la suspensión definitiva y completa del tratamiento antiplaquetario incrementa el riesgo de muerte (debido a trombosis de endoprótesis vasculares o IAM) hasta en un $50 \%$.

Previo a un procedimiento endoscópico de alto riesgo de hemorragia en pacientes con terapia antiplaquetaria dual se recomienda no suspender el AAS y sí suspender los antagonistas de los receptores P2Y12, previo consenso con el cardiólogo, hematólogo o el médico tratante.

El clopidogrel y el ticagrelor deben ser suspendidos 5 días y el prasugrel 7 días antes del procedimiento endoscópico, el cual debe realizarse en forma electiva.

Un metaanálisis reportó que el riesgo de HPP inmediata no se incrementó con el uso de AAS, pero el riesgo de HPP tardía incrementa con el uso de antagonistas P2Y12 y terapia dual respectivamente (AAS, RM: 1.7; IC 95\%: 1.0-2.4; $p=0.0009$; clopidogrel, RM: 9.7; IC 95\%: 3.1-30.8 y AAS + clopidogrel, RM: 3.4; IC $95 \%: 1.3-8.8)^{62}$.

El $60-70 \%$ de los eventos cardiovasculares graves se presentan dentro de los 7 a 10 días posteriores a la interrupción de la terapia antiplaquetaria ${ }^{13,32}$.

Los antagonistas del receptor P2Y12 deben ser reiniciados entre 24 y 48 horas después del procedimiento endoscópico en el que se haya asegurado la hemostasia endoscópica, sin embargo, se debe evaluar cada caso para evitar complicaciones hemorrágicas severas tras el procedimiento ${ }^{24,63}$.

\section{En pacientes con bajo riesgo} tromboembólico y que se someterán a un procedimiento endoscópico con alto riesgo de hemorragia deben suspenderse los antagonistas de la vitamina $K 5$ días antes del procedimiento y monitorizar la INR 1 día antes

\footnotetext{
Recomendación fuerte, calidad de la evidencia baja (GRADE 1C)

El uso de AVK se asocia a un riesgo elevado de hemorragia gastrointestinal, especialmente durante procedimientos endoscópicos terapéuticos considerados de alto riesgo, por lo que se recomienda su suspensión.
}

Considerando que su vida media aproximada es de 40 horas, se ha estimado que para alcanzar un valor de INR de 1.5 se requiere de 4 a 5 días, cuando se parte de un valor de INR entre 2 y 3 previo a su suspensión ${ }^{64,65}$; sin embargo se sugiere valoración cardiológica o hematológica para individualizar el número de días previos que deben suspenderse o disminuir la dosis con base en la INR inicial, además se debe monitorizar los valores de INR en las 24 horas antes del procedimiento.

Los AVK deberán reiniciarse en las primeras 24 horas después del procedimiento endoscópico, una vez se haya logrado y confirmado la hemostasia ${ }^{66}$.

\section{En pacientes con alto riesgo tromboembólico que se someterán a procedimientos endoscópicos con alto riesgo de hemorragia deben suspenderse los antagonistas de la vitamina $K 5$ días antes del procedimiento e iniciar terapia puente}

\section{Recomendación fuerte, calidad de la evidencia moderada (GRADE 1B)}

Existen condiciones clínicas de que por el elevado riesgo tromboembólico (p. ej., fibrilación auricular asociada a enfermedad valvular, particularmente estenosis mitral y las prótesis valvulares) son tratadas con medicamentos como los AVK.

Cualquier prótesis mecánica o biológica en posición mitral conlleva un elevado riesgo tromboembólico (> 10\% anual), mientras que de las prótesis en posición aórtica únicamente las mecánicas de tipo jaula/bola y de disco vasculante se asociaban a un riesgo elevado de tromboembolia. Otros pacientes con riesgo tromboembólico elevado son aquellos con múltiples prótesis valvulares o una sola en cualquier posición asociada a fibrilación auricular, disfunción ventricular, dilatación auricular, evento embólico previo o estado hipercoagulable ${ }^{4}$.

El AVK más utilizado en la mayoría de los estudios y ensayos clínicos es la warfarina, cuya efectividad de anticoagulación se mide con el valor de la INR ${ }^{67}$. A diferencia de los pacientes con riesgo tromboembólico bajo e intermedio, en los que se busca una INR entre 2.0 y 3.0, en los pacientes con riesgo tromboembólico elevado se recomienda una INR óptima entre 2.5 y $3.5^{68,69}$. El riesgo absoluto de un evento tromboembólico en pacientes en quienes se interrumpe la anticoagulación durante 4 a 7 días es aproximadamente del $1 \% 55$.

En un estudio multicéntrico fueron examinados 1,293 episodios de interrupción de warfarina en 1,024 
pacientes que se sometieron a una colonoscopia o a una cirugía dental u oftalmológica. De estos, solo el $7.1 \%$ fueron considerados de alto riesgo tromboembólico. La terapia puente con heparina perioperatoria se utilizó solo en el $8.3 \%$ de los casos. En 7 (RM: 0.7\%; IC 95\%: 0.3-1.4\%) casos se presentó un evento tromboembólico dentro de los primeros 30 días posteriores al procedimiento; ninguno de estos pacientes recibió terapia puente con heparina. En relación al desarrollo de hemorragia después del procedimiento, 6 casos (RM: 0.6\%; IC 95\%: 0.2-1.3\%) presentaron una hemorragia mayor (1 subdural espontánea, 4 gastrointestinales después de colonoscopia y 1 de tejidos blandos con síndrome compartimental), y 17 pacientes (RM: 1.7\%; IC 95\%: 1-2.6\%) experimentaron hemorragias menores. De estos 23 pacientes, 14 recibieron terapia puente con heparina (4 de los 6 con hemorragia mayor y 10 de los 17 con hemorragia menor $)^{70}$. El estudio concluye que una interrupción breve (5 días o menos) de warfarina antes de una intervención ambulatoria menor se asocia a un bajo riesgo de tromboembolia y que el riesgo de hemorragia clínicamente significativa debe ponderarse contra el riesgo tromboembólico antes de iniciar la terapia puente con heparina.

En pacientes con riesgo tromboembólico alto en tratamiento con AVK y que serán sometidos a un procedimiento endoscópico de alto riesgo de hemorragia se recomienda suspender los AVK 5 días previos al procedimiento e iniciar terapia puente. La INR disminuye $a<1.5$ en aproximadamente el $93 \%$ de los pacientes a los 5 días de suspendido el tratamiento. Se recomienda verificar que la INR se encuentre $\leq 1.5$ en las 24 horas previas al procedimiento. Los AVK deberán reiniciarse en las primeras 24 horas después del procedimiento endoscópico con hemostasia confirmada ${ }^{4,71}$.

La terapia puente debe iniciarse dentro de las 48 horas posteriores a la suspensión del antagonista de la vitamina $K$, suspenderse previamente al procedimiento, reiniciar al asegurar la hemostasia y mantenerla hasta alcanzar la INR terapéutica

\section{Recomendación fuerte, calidad de la evidencia baja (GRADE 1C)}

Para reducir el riesgo de eventos tromboembólicos, los pacientes tratados con AVK pueden cambiar a un anticoagulante de acción más breve (puenteo o terapia puente) en el periodo periendoscópico. La evidencia para el uso de heparinas no fraccionadas (HNF), heparinas de bajo peso molecular (HBPM) y ACOD como terapias de puente para procedimientos endoscópicos en pacientes con AVK es limitada y la mayoría de las veces se extrapola de los resultados de procedimientos invasivos electivos en general ${ }^{6,32,72}$.

Son indicaciones de terapia puente durante la interrupción temporal de AVK: fibrilación auricular no valvular con $\mathrm{CHA}_{2} \mathrm{DS}_{2}$-VASc $>2$, válvula mitral metálica, válvula protésica con fibrilación auricular, tromboembolismo venoso (TEV) en $<3$ meses y trombofilia severa $^{19}$ (Tabla 8).

En un estudio de 98 pacientes a quienes se realizó endoscopia (alta y/o baja) con terapia puente usando bemiparina (ultra-HBPM), no se presentaron eventos tromboembólicos y solo 2 episodios de hemorragia mayor no relacionada a la endoscopia ${ }^{73}$. Otro estudio en México no encontró diferencias significativas en la incidencia de trombosis ni eventos hemorrágicos mayor a los 30 días al comparar el uso de terapia puente con enoxaparina vs. ribaroxabán en pacientes sometidos a diversos procedimientos invasivos, incluyendo endoscopia ${ }^{74}$.

En pacientes con alto riesgo de tromboembolia se debe iniciar terapia puente (HNF, HBPM O ACOD) cuando la INR se encuentra por debajo de 2.0 antes del procedimiento endoscópico $0^{6,19,71,73}$ de la siguiente manera:

1. Iniciar terapia puente $24-48$ horas tras la suspensión del AVK.

2. La terapia puente debe suspenderse

- Si se utiliza HBPM SC: 24 horas previo al procedimiento,

- Si se utiliza HNF IV 4-6 horas antes y

- Si se usa alguno de los ACOD 24-48 horas antes.

3. La terapia puente se debe reiniciar después del procedimiento tan pronto como permita la hemostasia del paciente ( 24 horas después de un procedimiento de bajo riesgo de hemorragia y 48-72 horas después de un procedimiento de alto riesgo).

4. La terapia puente se debe continuar hasta que la INR (AVK) alcance un nivel terapéutico apropiado.

En procedimientos endoscópicos con alto riesgo de hemorragia deben suspenderse los anticoagulantes orales de acción directa 48 horas antes del procedimiento

\section{Recomendación fuerte, calidad de la evidencia baja (GRADE 1C)}

La farmacocinética y farmacodinámica de los ACOD es diferente a la de los AVK; los primeros alcanzan un 
Tabla 8. Estratificación de riesgo tromboembólico

\begin{tabular}{|c|c|c|c|}
\hline \multicolumn{4}{|c|}{ Indicaciones para anticoagulación } \\
\hline $\begin{array}{l}\text { Estratificación de riesgo } \\
\text { para eventos trombóticos }\end{array}$ & Válvula cardíaca mecánica & Fibrilación auricular & Tromboembolia venosa \\
\hline Riesgo alto & $\begin{array}{l}\text { Cualquier válvula aórtica de } \\
\text { disco o caged ball } \\
\text { EVC o AIT reciente (tiempo } \\
\text { menor a } 6 \text { meses) }\end{array}$ & $\begin{array}{l}\text { Score CHA2DS2-VASc > } 2 \\
\text { Evento vascular cerebral o AIT } \\
\text { reciente (tiempo menor a } 3 \\
\text { meses) } \\
\text { Enfermedad reumática valvular }\end{array}$ & $\begin{array}{l}\text { TEV reciente (tiempo menor a } 3 \\
\text { meses) } \\
\text { Trombofilia severa* }\end{array}$ \\
\hline Riesgo moderado & $\begin{array}{l}\text { Válvula aórtica bileaflet y > } 1 \\
\text { de los siguientes: fibrilación } \\
\text { auricular, EVC o AIT previo, } \\
\text { hipertensión, diabetes, ICC, } \\
\text { edad > } 75 \text { años }\end{array}$ & Score CHA2DS2-VASc de 1 & $\begin{array}{l}\text { TEV en los previos } 3-12 \text { meses } \\
\text { TEV recurrente } \\
\text { Cáncer activo (con paliación en } \\
\text { los } 6 \text { meses previos) } \\
\text { Trombofilia no severa* }\end{array}$ \\
\hline Riesgo bajo & $\begin{array}{l}\text { Válvula aórtica bileaflet sin } \\
\text { fibrilación auricular y ningún } \\
\text { otro factor de riesgo para EVC }\end{array}$ & Score CHA2DS2-VASc de 0 & $\begin{array}{l}\text { TEV > } 12 \text { meses previos y sin } \\
\text { ningún otro factor de riesgo }\end{array}$ \\
\hline
\end{tabular}

*Trombofilia severa: deficiencia de proteína C, proteína S o antitrombina, anticuerpos antifosfolipidos. Trombofilia no severa: heterocigoto para factor V de Leiden o protrombina G20210A.

EVC: evento vascular cerebral; AIT: ataque isquémico transitorio; ICC: insuficiencia cardíaca congestiva; CHA2DS2-VASc: insuficiencia cardiaca, hipertensión edad > 75 años, diabetes mellitus, ictus previo, enfermedad vascular, edad entre 65 y 74 años, sexo femenino; TEV: tromboembolismo venoso.

pico máximo de concentración más temprano y tienen vida media más corta ${ }^{75}$; sin embargo, debido a que la intensidad de su efecto no es medible de forma precisa, la estrategia más segura consiste en suspender su administración durante el tiempo necesario para que estos sean eliminados del organismo y no tengan efecto anticoagulante al momento del estudio.

Se estima que el lapso necesario para que los ACOD no tengan efecto clínico es el equivalente a dos veces su vida media, por lo que para la realización de procedimientos endoscópicos con alto riesgo de hemorragia se sugiere la suspensión del ACOD 48 horas antes ${ }^{76}$.

Se ha demostrado que el riesgo de hemorragia es mayor en pacientes con uso de dabigatrán y deterioro de la función renal (depuración de creatinina: $30-50 \mathrm{ml} / \mathrm{min})^{77,78}$, por lo que en este grupo de pacientes se recomienda suspender los ACOD durante al menos 72 horas antes de cualquier procedimiento endoscópico con alto riesgo de hemorragia.

Debido a la falta de evidencia adecuada y al rápido inicio de acción nuestra recomendación es reiniciar los ACOD 24 a 48 horas tras el procedimiento.

\section{Conclusiones}

Las guías de la AMEG sobre el manejo de la terapia antitrombótica durante procedimientos endoscópicos son el resultado de un análisis multidisciplinario basado en la evidencia disponible en hasta el momento de su elaboración y en la opinión de especialistas expertos. La síntesis de los enunciados y su clasificación GRADE se muestra en la tabla 9.

Estas guías tienen la intención proporcionar recomendaciones en puntos considerados clave por parte de los participantes que ayuden al adecuado manejo de la terapia antitrombótica durante procedimientos endoscópicos a los médicos relacionados con el cuidado de estos pacientes.

Es importante recordar que las presentes guías deben interpretarse e implementarse con base en cada caso individual y en conjunto con un equipo multidisciplinario.

\section{Declaración de conflictos de interés}

Los siguientes participantes declaran no tener conflicto de interés o relación financiera que declarar: Dr. Mario Peláez-Luna, Dra. Claudia Isabel Blanco-Vela, Dra. Clara Luz Martínez, Dr. Sergio Solana-Sentíes, Dr. Orlando Bada-Yllán, Dr. Jony Cerna-Cardona, Dr. Héctor Espino-Cortés, Dr. Yu Ling Lee-Tsai, Dr. Hugo Roberto Leytón-Rivera, Dra. Claudia Martínez-Camacho, Dr. Enrique Murcio-Pérez, Dr. Francisco Alejandro Ovando-Zambrano, Dr. Fernando Pérez-Aguilar, Dr. Roberto Ramos-González, Dr. Ángel Andrés Reyes-Dorantes, Dr. Carlos Alberto Reyes-Gómez, Dra. Xochiquetzal Sánchez-Chávez, Dr. Javier Ignacio Vinageras-Barroso y Dr. Luis Eduardo Zamora-Nava.

Los siguientes participantes declaran tener algún conflicto de interés o relación financiera: la Dra. 
Tabla 9. Síntesis de las Guías

\section{Definición de agentes antitrombóticos}

I.1 Los anticoagulantes son sustancias químicas que de manera directa o indirecta inhiben la formación del coágulo y están indicados en la prevención y tratamiento de enfermedad tromboembólica. Grade 1A

I.2 Los antiplaquetarios son sustancias que disminuyen la función plaquetaria mediante inhibición irreversible de la ciclooxigenasa 0 del receptor P2Y12 y están indicados en la prevención y tratamiento de la enfermedad tromboembólica arterial. Grade 1A

I.3 La frecuencia de hemorragia en procedimientos endoscópicos en pacientes con terapia antitrombótica depende del tipo de procedimiento realizado. Grade 1B

I.4 La frecuencia de tromboembolia posterior a la suspensión de la terapia antitrombótica depende del riesgo tromboembólico del paciente. Grade 1B

Agentes utilizados para revertir el efecto anticoagulante

I.5 La decisión de revertir la anticoagulación deberá ser evaluada por un equipo multidisciplinario, dependerá del riesgo tromboembólico del paciente y del riesgo de hemorragia asociada al procedimiento. Grade $\mathbf{1 A}$

\section{Estratificación de riesgos}

II.1 Se recomienda estratificar los procedimientos endoscópicos en alto y bajo riesgo de acuerdo con la frecuencia de hemorragia. Grade 1B

\section{Manejo de pacientes en procedimientos de bajo riesgo de hemorragia}

III.1 En procedimientos endoscópicos con bajo riesgo de hemorragia no es necesario la estratificación del riesgo tromboembólico. Grade 1B

III.2 En procedimientos endoscópicos con bajo riesgo de hemorragia no se requiere suspender antiplaquetarios. Grade 1C

III.3 En procedimientos endoscópicos de bajo riesgo de hemorragia sugerimos continuar los antagonistas de la vitamina K. Grade 1C

III.4 En los procedimientos endoscópicos con bajo riesgo de hemorragia se sugiere continuar la terapia con anticoagulantes orales directos. Grade 1C

\section{Manejo de pacientes con alto riesgo de hemorrragia}

IV.1 En pacientes con bajo riesgo tromboembólico que serán sometidos a procedimientos endoscópicos con alto riesgo de hemorragia, la terapia con ácido acetilsalicílico debe continuarse. Grade 1B

IV.2 En pacientes que reciben terapia dual antiplaquetaria con alto riesgo tromboembólico y que se someterán a procedimientos endoscópicos con alto riesgo de hemorragia, se debe continuar el ácido acetilsalicílico pero suspender los antagonistas del receptor P2Y12. Grade 1B

IV.3 En pacientes con bajo riesgo tromboembólico y que se someterán a un procedimiento endoscópico con alto riesgo de hemorragia deben suspenderse los antagonistas de la vitamina K 5 días antes del procedimiento y monitorizar la INR 1 día antes. Grade 1C

IV.4 En pacientes con alto riesgo tromboembólico que se someterán a procedimientos endoscópicos con alto riesgo de hemorragia deben suspenderse los antagonistas de la vitamina K 5 días antes del procedimiento e iniciar terapia puente. Grade 1B

IV.5 La terapia puente debe iniciarse dentro de las 48 horas posteriores a la suspensión del antagonista de la vitamina K, suspenderse previo al procedimiento, reiniciar al asegurar la hemostasia y mantenerla hasta alcanzar la INR terapéutica. Grade 1C

IV.6 En procedimientos endoscópicos con alto riesgo de hemorragia deben suspenderse los anticoagulantes orales de acción directa 48 horas previas al procedimiento. Grade 1C

INR: razón internacional normalizada.

\section{Angélica Hernández-Guerrero es conferencista de Olympus Inc. y Boston Scientific.}

\section{Bibliografía}

1. Hallas J, Dall M, Andries A, Andersen BS, Aalykke C, Hansen JM, et al. Use of single and combined antithrombotic therapy and risk of serious upper gastrointestinal bleeding: population based case-control study. BMJ. 2006;333:726.

2. Bhala N, Taggar JS, Rajasekhar P, Banerjee A. Anticipating and managing bleeding complications in patients with coronary stents who are receiving dual antiplatelet treatment. BMJ. 2011;343:d4264.

3. Verma AM, Bhala N, Antithombotic therapy and invasive procedures. Letter to the editor. N Engl J Med. 2013;369:1077.

4. Baron TH, Kamath PS, McBane RD. Management of antithrombotic therapy in patients undergoing invasive procedures. N Engl J Med. 2013; 368:2113-24.

5. Horlocker TT, Wedel DJ, Rowlingson JC, Enneking FK, Kopp SL, Benzon HT, et al. Regional anesthesia in the patient receiving antithrombotic or thrombolytic therapy: American Society of Regional Anesthesia and Pain Medicine Evidence-Based Guidelines (Third Edition). Reg Anesth Pain Med. 2010;35;64-101.

6. Douketis JD, Spyropoulos AC, Spencer FA, Mayr M, Jaffer AK, Eckman $\mathrm{MH}$, et al. Perioperative management of antithrombotic therapy:
Antithrombotic therapy and prevention of thrombosis, $9^{\text {th }}$ ed: American College of Chest Physicians Evidence-Based Clinical Practice Guidelines. Chest. 2012;141(2 Suppl):e326S-e350S. [Erratum, Chest 2012; 141:1129.]

7. Garcia DA, Baglin TP, Weitz JI, Samama MM. Parenteral anticoagulants: antithrombotic therapy and prevention of thrombosis, $9^{\text {th }}$ ed: American College of Chest Physicians Evidence-Based Clinical Practice Guidelines. Chest. 2012;141(2 Suppl):e24S-e43S. [Erratum, Chest 2012; 141:1369.]

8. Veitch AM, Vanbiervliet G, Gershlick AH, Boustiere C, Baglin TP Smith LA, et al. Endoscopy in patients on antiplatelet or anticoagulant therapy, including direct oral anticoagulants: British Society of Gastroenterology (BSG) and European Society of Gastrointestinal Endoscopy (ESGE) guidelines. Endoscopy. 2016;48(4):385-402.

9. Fink A, Kosecoff J, Chassin M, Brook RH. Consensus methods: characteristics and guidelines for use. Am J Public Health. 1984;74:979-83.

10. Grading tutorial [Internet]. UpToDate $₫$, Wolters Kluwer [consultado el 15 de marzo 2017]. Disponible en: http://www.uptodate.com/home/grading-tutorial.

11. Guyatt GH, et al. GRADE: an emerging consensus on rating quality of evidence and strength of recommendations. BMJ. 2008;336:924-6.

12. Mega JL, Simon T. Pharmacology of antithrombotic drugs; an assessment of oral antiplatelet and anticoagulant treatments. Lancet. 2015; 386:281-91.

13. González M, Pérez A. Manejo de la antiagregación y anticoagulación periendoscópica: introducción a antiagregantes y anticoagulantes orales más novedosos. Rev Esp Enferm Dig. 2016;108:89-96. 
14. Badimon L, Vilahur G. Mecanismos de acción de los diferentes agentes antiplaquetarios. Rev Esp Cardiol. 2013;13(B):8-15.

15. Lloyd-Jones D, Adams R, Carnethon M, et al. Heart disease and stroke statistics-2009 update: a report from the American Heart Association Statistics Committee and Stroke Statistics Subcommittee. Circulation. 2009;119:480-6

16. Ara N, lijima K, Maejima R, Kondo $\mathrm{Y}$, et al. Prospective analysis of risk for bleeding after endoscopic biopsy without cessation of antithrombotics in Japan. Dig Endosc. 2015;27(4):458-64.

17. Shibuya $T$, Nomura $O$, Kodani $T$, et al. Continuation of antithrombotic therapy may be associated with a high incidence of colonic post-polypectomy bleeding. Dig Endosc. 2017;29(3):314-21.

18. Kono $\mathrm{Y}$, Matsubara $\mathrm{M}$, Toyokawa $\mathrm{T}$, et al. Multicenter prospective study on the safety of upper gastrointestinal endoscopic procedures in antithrombotic drug users. Dig Dis Sci. 2017;62(3):730-8.

19. Abraham NS. Management of antiplatelet agents and anticoagulants in patients with gastrointestinal bleeding. Gastrointest Endosc Clin N Am. 2015;25:449-62.

20. Chan FKL, Goh KL, Reddy N, et al. Management of patients on antithrombotic agents undergoing emergency and elective endoscopy: joint Asian Pacific Association of Gastroenterology (APAGE) and Asian Pacific Society for Digestive Endoscopy (APSDE) practice guidelines. Gut. 2018;67(3):405-17.

21. Pareek M, Kristensen S, Grove E. Cardiovascular events after discontinuation of low-dose aspirin. J Thorac Dis. 2018;10(1):75-8.

22. Sundström J, Hedberg J, Thuresson M, et al. Low-dose aspirin discontinuation and risk of cardiovascular events. A Swedish nationwide, population-based cohort study. Circulation. 2017;136:1183-92.

23. Baigent $C$, Blackwell $L$, Collins $R$, et al. Aspirin in the primary and secondary prevention of vascular disease: collaborative meta-analysis of individual participant data from randomised trials. Lancet. 2009;373: 1849-60.

24. Eisenberg M. Richard P, Libersan D. et al. Safety of short-term discontinuation of antiplatelet therapy in patients with drug-eluting stents. Circulation. 2009;119:1634-42.

25. Abraham N, Noseworthy P, Yao X. et al. Gastrointestinal safety of direct oral anticoagulants: A large population-based study. Gastroenterol. 2017;152:1014-22.

26. Risk factors for stroke and efficacy of antithrombotic therapy in atrial fibrillation. Analysis of pooled data from five randomized controlled trials [published erratum appears in Arch Intern Med 1994;154:2254]. Arch Intern Med. 1994:154:1449-57.

27. Hui AJ, Wong RM, Ching JY et al. Risk of colonoscopic polypectomy bleeding with anticoagulants and antiplatelet agents: analysis of $1657 \mathrm{ca}$ ses. Gastrointest Endosc. 2004;59:44-8.

28. Cho SJ, Choi IJ, Kim CG et al. Aspirin use and bleeding risk after endoscopic submucosal dissection in patients with gastric neoplasms. Endosc. 2012;44:114-21.

29. Takeuchi T, Ota K, Harada S et al. The postoperative bleeding rate and its risk factors in patients on antithrombotic therapy who undergo gastric endoscopic submucosal dissection. BMC Gastroenterol. 2013;13:136.

30. Bahin FF, Naidoo M, Williams SJ et al. Prophylactic endoscopic coagulation to prevent bleeding after wide-field endoscopic mucosal resection of large sessile colon polyps. Clin Gastroenterol Hepatol. 2015;13: 724-30.

31. Burgess NG, Metz AJ, Williams SJ et al. Risk factors for intraprocedural and clinically significant delayed bleeding after wide-field endoscopic mucosal resect. Clin Gastroenterol Hepatol. 2014;12:651-61.

32. Acosta RD, Abraham NS, Chandrasekhara V, et al. The management of antithrombotic agents for patients undergoing GI endoscopy. Gastrointest Endosc. 2016;83:3-16.

33. Zakko L, Rustagi T, Douglas M, et al. No benefit from platelet transfusion for gastrointestinal bleeding in patients taking antiplatelet agents. Clin Gastroenterol Hepatol. 2017;15:46-52.

34. Tsu LV, Dienes JE, Dager WE. Vitamin $\mathrm{K}$ dosing to reverse warfarin based on INR, route of administration, and home warfarin dose in the acute/critical care setting. Ann Pharmacother. 2012;46:1617-26.

35. Moreno-Carrillo A, Pulido-Arenas J, Bejarano-Zuleta A. Concentrados de complejo protrombínico en el servicio de urgencias. Med Int Méx. 2014;30:56-63.

36. Klein L, Peters J, Miner J, Gorlin J. Evaluation of fixed dose 4-factor prothrombin complex concentrate for emergent warfarin reversal. Am J Emerg Med. 2015;33(9):1213-8.

37. Yasaka M, Sakata T, Naritomi H, Minematsu K. Optimal dose of prothrombin complex concentrate for acute reversal of oral anticoagulation. Thromb Res. 2005;115(6):455-9.

38. Glund, S. et al. A randomised study in healthy volunteers to investigate the safety, tolerability and pharmacokinetics of idarucizumab, a specific antidote to dabigatran. Thromb Haemost. 2015;113:943-51.

39. Glund, S. et al. Safety, tolerability, and efficacy of idarucizumab for the reversal of the anticoagulant effect of dabigatran in healthy male volunteers: a randomised, placebo-controlled, double-blind phase 1 trial. Lancet. $2015 ; 386: 680-90$
40. Pollack CV, Reilly PA. Idarucizumab for dabigatran reversal. $\mathrm{N}$ Engl J Med. 2015;373:511-20.

41. Siegal, D. M. et al. Andexanet al.a for the reversal of factor Xa inhibitor activity. N Engl J Med. 2015;373:2413-24.

42. Veitch A, Baglin T, Gershlick A, Harnden S, Tighe R, et al. Guidelines for the management of anticoagulant and antiplatelet therapy. GUT. 2008:57:1322-29.

43. Johnson B, Basson MD. Absence of complications after endoscopic mucosal biopsy. Dig Dis. 2018;36(4):328-32.

44. Dormann A, Meisner S, Verin N, et al. Self-expanding stents for gastro-duodenal malignancies: systematic review of clinical effectiveness. Endoscopy. 2004;36:543-50.

45. Gerson LB, Tokar J, Chiorean M, et al. Complications associated with double balloon enteroscopy at nine US centers. Clin Gastroenterol Hepatol. 2009;7:1177-82

46. Corte C, Burger D, Horgan G, Bailey A, East J. Postpolypectomy haemorrhage following removal of large polyp using mechanical haemostasis or epinephrine: a meta-analysis. United European Gastroenterol J. 2014; 2(2):123-30

47. Yang XM, Hu B. Endoscopic sphincterotomy plus large-balloon dilation vs. endoscopic sphincterotomy for choledocholithiasis: A meta-analysis. World J Gastroenterol. 2013;19(48):9453-60.

48. Andriulli A, Loperfido S, Napolitano G, Niro G, Valvano MR, Spirito F, et al. Incidence rates of post-ERCP complications: a systematic survey of prospective studies. Am J Gastroenterol. 2007;102(8):1781-8.

49. Lozoya-González D, Peláez-Luna M, Farca-Belsaguy A, Salceda Otero JC, Vazquéz Ballesteros E. Percutaneous endoscopic gastrostomy complication rates and compliance with the American Society for Gastrointestinal Endoscopy guidelines for the management of antithrombotic therapy. J Parenter Enteral Nutri. 2012;36:226-30.

50. Kataoka Y, Tsuji Y, Sakaguchi Y, Minatsuki C, Asada-Hirayama I, et al. Bleeding after endoscopic submucosal dissection: Risk factors and preventive methods. Worls J Gastroenterol. 2016;22(26):5927-35.

51. Ono S, Fujishiro M, Kodashima S, Takahashi Y, Minatsuki C, Mikami-Matsuda R, et al. Evaluation of safety of endoscopic biopsy without cessation of antithrombotic agents in Japan. J Gastroenterol. 2012; 47(7):770-4

52. Sieg A, Hachmoeller-Eisenbach U, Eisenbach T. Prospective evaluation of complications in outpatient GI endoscopy: a survey among German gastroenterologists. Gastrointest Endosc. 2001;53(6):620-7.

53. Baron TH, Harewood GC. Endoscopic balloon dilation of the biliary sphincter compared to endoscopic biliary sphincterotomy for removal of common bile duct stones during ERCP: A metaanalysis of randomized, controlled trials. Am J Gastroenterol. 2004;99:1455-60.

54. Lee SY, Tang SJ, Rockey DC, et al. Managing anticoagulation and antiplatelet medications in GI endoscopy: a survey comparing the East and the West. Gastrointest Endosc. 2008;67:1076-81.

55. Gerson LB, Gage BF, Owens DK, et al. Effect and outcomes of the ASGE guidelines on the periendoscopic management of patients who take anticoagulants. Am J Gastroenterol. 2000;95:1717-24.

56. Anderson MA, Ben-Menachem T, Gan SI, et al. Management of antithrombotic agents for endoscopic procedures. Gastrointest Endosc. 2009;70(6):1060-7.

57. Spyropoulos AC, Douketis JD, Gerotziafas G, et al. Periprocedural antithrombotic and bridging therapy: recommendations for standardized reporting in patients with arterial indications for chronic oral anticoagulant therapy. J Thromb Haemost. 2012;10:692-4.

58. Heidbuchel $H$, Verhamme $P$, Alings $M$, et al. European Heart Rhythm Association Practical Guide on the use of new oral anticoagulants in patients with non-valvular atrial fibrillation. Europace. 2013;15:625-51.

59. Beyer-Westendorf J, Gelbricht V, Forster K, et al. Peri-interventional management of novel oral anticoagulants in daily care: results from the prospective Dresden NOAC registry. Eur Heart J. 2014;35(28):1888-96.

60. Nelson BD, Freeman ML. Major hemorrhage from endoscopic sphicnterotomy: risk factor analysis. J Clin Gastroenterol. 1994;19:283-7.

61. Metz AJ, Bourke MJ, Moss A. et al. Factors that predict bleeding following endoscopic mucosal resection of large colonic lesions. Endoscopy. 2011; 43:506-11.

62. Salman D, Gerson LB. Systematic review with meta-analysis: The risk of gastrointestinal haemorrhage post-polypectomy in patients receiving anti-platelet, anti-coagulant and/or thienopyrdine medications. Aliment Pharmacol Ther. 2015:42:949-56.

63. Boustière $C$ et al. Endoscopy and antiplatelet agents. European Society of Gastrointestinal Endoscopy (ESGE) Guideline. Endoscopy. 2011; 43:445-58.

64. Zullo A, Hassan C, Radaelli F. Gastrointestinal endoscopy in patients on anticoagulat therapy and antiplatelet agents. Ann Gastroenterol. 2017;30:7-14.

65. White $\mathrm{RH}$, McKittrick T, Hutchinson R, et al.Temporary discontinuation of warfarin therapy: Changes in the international normalized ratio. Ann Intern Med. 1995;1:40-4

66. Keeling D, Baglin T. Tait C, et al. Guidelines on oral anticoagulation with warfarin-four edition. $\mathrm{Br} J$ Haematol. 2011;154:311-24. 
67. Durán-Parrondo C, Rodríguez-Moreno C, et al. Anticoagulación oral. An Med Interna. 2003;20;7:377-84.

68. Hirsh J, Dalen JE, et al. Oral anticoagulants. Mechanism of action, clinical effectiveness, and optimal therapeutic range. Chest. 1992;102;4: 312-26S.

69. Pibarot P, Dumesnil JG, et al. Prosthetic heart valves. Selection of de optimal prosthesis and long-term management. Circulation. 2009;119: 1034-48.

70. García DA, Regan S, et al. Risk of thromboembolism with short-term interruption of warfarin therapy. Arch Intern Med. 2008;168(1):63-9.

71. Schulman S, Elbazi R, et al. Clinical factors influencing normalization of prothrombin time after stopping warfarin: a retrospective cohort study. Thromb J. 2008;6:15.

72. Kato M, Uedo N, Hokimoto S, et al. Guidelines for gastroenterological endoscopy in patients undergoing antithrombotic treatment: 2017. Appendix on anticoagulants including direct oral anticoagulants (DOACs) Dig Endosc. 2018;30(4):433-40.
73. Constans M, Santamaria A, Mateo J, et al. Low-molecular-weight heparin as bridging therapy during interruption of oral anticoagulation in patients undergoing colonoscopy or gastroscopy. Int J Clin Pract. 2007; 61:212-7.

74. Majluf Cruz A, Moreno-Hernandez M, Garcia-Chavez J, et al. Bridging with rivaroxaban in patients with chronic use of vitamin $\mathrm{K}$ antagonists. European Society of Cardiology, ESC Congress; 2011 Aug 27; Paris, France. Eur Heart J. 2011;32:414.

75. Jackson LR, Becker R. Novel anticoagulants: pharmacology, coagulation measures, and considerations for reversal. J Thromb Thrombolysis. 2014;37(3):380-91.

76. Baglin T. Clinical use of new oral anticoagulant drugs: dabigatran and rivaroxabán. Br J Haematol. 2013;163:160-7.

77. Connolly SJ, Ezekowitz MD, Yusuf S, et al. Dabigatran versus warfarin in patients with atrial fibrillation. N Engl J Med. 2009;361:1139-51.

78. Schulman S, Carrier M, Lee AY et al. Perioperative management of dabigatran: a prospective cohort study. Circulation. 2015;132:167-73. 